\title{
Comparative study in leg telangiectasias treatment with Nd:YAG laser and sclerotherapy
}

\author{
GABRIEL IANOSI $^{1}$, SIMONA IANOSI ${ }^{2}$, MADALINA XENIA CALBUREANU-POPESCU ${ }^{3}$, \\ CRISTINA TUTUNARU ${ }^{2}$, DANIELA CALINA ${ }^{4}$ and DANIELA NEAGOE ${ }^{5}$
}

\begin{abstract}
Departments of ${ }^{1}$ Surgery and ${ }^{2}$ Dermatology, Medical Center Dr. Ianosi, University of Medicine and Pharmacy of Craiova, 200000 Craiova; ${ }^{3}$ Department of Applied Mechanics and Civil Buildings, Faculty of Mechanics, University of Craiova, 200512 Craiova; ${ }^{4}$ Department of Farmacology, University of Medicine and Pharmacy of Craiova; ${ }^{5}$ Department of Internal Medicine, Medical Center Dr. Ianosi, University of Medicine and Pharmacy of Craiova, 200000 Craiova, Romania
\end{abstract}

Received August 13, 2018; Accepted September 24, 2018

DOI: $10.3892 /$ etm.2018.6985

\begin{abstract}
Telangiectasias and reticular veins of the lower extremities are common lesions. Sclerotherapy is considered the gold standard for treatment. The aim of our prospective randomized study was to compare the efficacy and safety of hypertonic $20 \%$ saline/2\% lignocaine (HS) versus polidocanol $0.5 \%$ (POL) versus long-pulsed neodymium:ytrium aluminium garnet (Nd:YAG) laser (LAS) treatments of leg telangiectasias in women, using each patient as her own control. We included in this study 285 women with primary leg telangiectasias and reticular veins $\left(\mathrm{C}_{1 \mathrm{~A}} \mathrm{E}_{\mathrm{p}} \mathrm{A}_{\mathrm{S1}} \mathrm{P}_{\mathrm{N}}\right)$ in order to be treated with sclerotherapy or laser. One leg was treated with either LAS, POL or HS. The other leg received, randomly, one other of these treatments. At the end there were 190 legs treated with each method. There were two sessions at 8-week interval. Assessment of vessel clearing and complications was conducted 2 months after each session using before and after photographs of the leg vessels using a six-point scale from 0 (no change) to 5 (100\% cleared). For telangiectasias under $1 \mathrm{~mm}$ diameter LAS was better $(\mathrm{RR}=9.72, \mathrm{P}<0.0001)$ than $\mathrm{HS}$ and also POL was better $(\mathrm{RR}=2.70, \mathrm{P}=0.003)$; for telangiectasias over $1 \mathrm{~mm}$ diameter LAS and POL were better too $(\mathrm{R}=2.70$, $\mathrm{P}=0.003)$ respectively $(\mathrm{R}=1.44, \mathrm{P}=0.00756)$. For telangiectasias under $1 \mathrm{~mm}$ LAS treatment is clearly superior to POL treatment. For telangiectasias over $1 \mathrm{~mm}$ the hazard regression model showed a hazard ratio of $3.97(\mathrm{P}=0.047)$ for $\mathrm{LAS}$ and $4.96(\mathrm{P}=0.486)$ for $\mathrm{POL}$ vs. HS treatment. In conclusion, telangiectasias and reticular veins of the lower extremities can be successfully treated with Nd:YAG laser or sclerotherapy.
\end{abstract}

Correspondence to: Dr Simona Ianosi, Department of Dermatology, Medical Center Dr. Ianosi, University of Medicine and Pharmacy of Craiova, 99 Carol I Bvd., Dolj County, 200000 Craiova, Romania

E-mail: gianosi@hotmail.com; office@drianosi.ro

Key words: telangiectasias treatment, laser, sclerotherapy
Nd:YAG laser is recommended in treating small telangiectasias (under $1 \mathrm{~mm}$ diameter) while sclerotherapy with polidocanol is more efficient as long as telangiectasias diameter is growing.

\section{Introduction}

Chronic venous insufficiency is a disease that affects up to one third of the population, from young adults to the elderly $(1,2)$. Some studies (3) showed that if an active diagnostic system is used, the condition can be seen in $2 / 3$ of the population $(1,3)$. There have been several suggested definitions of this condition in order to encompass both the classification and the line of treatment (1). Currently, the Comprehensive Classification System for Chronic Venous Disorders (CEAP) is mostly accepted by the specialists, even though there are plenty of proposed improvements (1).

The venous insufficiency treatment of the lower limbs is according to the stage of the disease. There are efficiently proven methods such as liquid sclerotherapy and long-pulsed neodymium ytrium:aluminium garnet laser (Nd:YAG) for telangiectasias $(4,5)$.

Sclerotherapy of the varicose veins of the lower limbs is a medical procedure that consists of damaging the blood wall (endothelium but also some other surrounding structures) by injecting a certain chemical solution $(6,7)$. This leads to the sclerosis of the blood vessel, following the destruction of the endothelium. Despite the fact that the thrombosis is not the aim of this procedure, this phenomenon happens in a certain percentage of the vessel that undergo sclerotherapy (4).

The laser acts on the skin by converting absorbed light energy in thermal energy that will intensely heat certain cutaneous compounds called chromophores (5). They have different grades of light absorption depending on the wavelength. Nd:YAG laser with a wavelength of $1064 \mathrm{~nm}$, acts mainly on haemoglobin and heats it suddenly causing the destruction of the blood wall (8). The effect is almost instant, the destruction of the endothelium and the surrounding structures being seconded by vascular sclerosis and afterwards by remodelation, same as in sclerotherapy.

The aim of our study was to evaluate the efficacy and safety of hypertonic $20 \%$ saline/2\% lignocaine (HS) versus 
polidocanol (POL, $0.5 \%$ ) versus Nd:YAG laser (LAS) in the treatment of leg telangiectasias in women.

\section{Patients and methods}

During a period of 6 months, between September 2016 and February 2017 we included in this study 285 women (570 legs) with primary leg telangiectasias and reticular veins $\left(\mathrm{C}_{1 \mathrm{~A}} \mathrm{E}_{\mathrm{p}} \mathrm{A}_{\mathrm{S1}} \mathrm{P}_{\mathrm{N}}\right)$ in order to be treated with sclerotherapy or laser.

The study was conducted in accordance with the World Medical Association Declaration of Helsinki and was approved by the Institutional Ethics Committee of the Medical Center Dr. Ianosi (no. ETIC 6/2016; Craiova, Romania). Informed written consent was obtained from each patient.

Inclusion criteria aimed for patients over 18 with primary leg telangiectasias up to $2 \mathrm{~mm}$ in diameter $\left(\mathrm{C}_{1 \mathrm{~A}} \mathrm{E}_{\mathrm{p}} \mathrm{A}_{\mathrm{S1}} \mathrm{P}_{\mathrm{N}}\right)$ as single objective sign and those that accepted to enter the study signed the informed consent form. We used dedicated scales that measured vessels diameters between 1 and $10 \mathrm{~mm}$.

Exclusion criteria were the following: i) Patients with symptoms associated with telangiectasias $\left(\mathrm{C}_{1 \mathrm{~S}}\right)$; ii) patients with superficial venous reflux assessed with Doppler ultrasound of the lower limbs; iii) patients with deep venous thrombosis or post-thrombotic syndrome $\left(\mathrm{E}_{\mathrm{S}}\right)$; iv) pregnant or breastfeeding patients; and v) patients with neoplasms or other systemic conditions or under chronic treatment for any other disease.

The study group was divided in three equal groups of 190 lower limbs each: HS group was treated with hypertonic: $20 \%$ saline $/ 2 \%$ lignocaine, POL group with polidocanol: $0.5 \%$ (Aetoxysklerol; Kreussler Inc., Wiesbaden, Germany) and LAS group with Nd:YAG laser with a wavelength of 1064 nm (StarLux 500; Palomar Technologies, Carlsbad, CA, USA) platform with a $3 \mathrm{~mm}$ spot, pulse length of $30 \mathrm{msec}$ and fluency between 290 and $350 \mathrm{~J} / \mathrm{cm}^{2}$. The patient was included in the study as 'first come first served' principle and each patient received different treatment on the lower limbs. We randomised the type of the treatment on each leg. There were two identical sessions at 60-day interval. Assessment of vessel clearing and complications was conducted at 60 and 120 days. Investigator's evaluation was made using before and after photographs of the leg vessels using a six-point scale: 0 , no change; $1,1-20 \%$ cleared; $2,21-40 \%$ cleared; $3,41-60 \%$ cleared; 4, 61-80\% cleared; and 5, 81-100\% cleared.

Aside from the major objective, comparative evaluation of the efficacy of the sclerosing treatment (chemical or thermal), we also followed the rate of the local complications (burns, hypo- and hyperpigmentation, and thrombosis).

Statistical analysis. The data were introduced into Microsoft Excel for transversal and longitudinal data statistical analysis. Numerical variables were expressed as mean \pm standard deviation (mean $\pm \mathrm{SD}$ ). Proportions were always expressed as percentages. The $\chi^{2}$ test was used for determine if there is a significant relationship between two variables. (significant difference between the expected frequencies and the observed frequencies in one or more categories). $\mathrm{P}<0.05$ was considered to indicate a statistically significant difference.

Statistical analysis of the treatment effects is a procedure that helps to prove causality hypothesis and is specially developed for comparing the effect of multiple treatments in homogeneous group of patients with a given disease. The average treatment effect was calculated among the treated and potential outcome mean as measures of treatment effects.

The longitudinal data analysis included calculation of incidence rates, statistical modelling using longitudinal regression models and time-to-event analysis. Statistical modelling used longitudinal regression models, namely random-effects ordered logistic regression. By accounting for randomness of the treatment outcome that is inherent to biological systems, the model can better predict the chance for success of every treatment type, compared with the usual transversely applied regression models which ignore the time factor.

The time-to-event analysis (survival analysis) was performed using the good/very good result as failure variable and time to event expressed in whole months from the beginning of the treatment. This produced hazard ratios which can be assimilated to risk ratios (RR) in the transverse analysis and which can be used to compare treatment success rates per unit of time, so in the future the patients can make informed decisions on the type of treatment outcomes and time required.

\section{Results}

Forty-one of 285 patients (82 legs) could not be followed till the end of the study. Only 244 patients (488 legs) were evaluated during both visits (after 60 and 120 days). After the last visit there were 169 legs in the POL group, 154 in HS group and 165 in LAS group.

There were no deaths or major complications (deep venous thrombosis, severe burns or ischemic complications) reported. The minor complications were represented by cutaneous burns (on 14 legs) and 31 hyperpigmentation with no statistic correlation.

At the end of all the two sessions of treatment, of the 488 legs, 123 had a moderate overall result, 360 had good and very good overall results ( 4 and 5 on our clearance scale), and 5 had a limited modest results ( 3 in our scale). Very good results were encountered in $72(43.63 \%)$ of 165 legs treated with LAS and good results were encountered in 74 (44.84\%) legs. There were very good results in $19(11.24 \%)$ of 169 legs treated with POL and good results in 97 (57.39\%). Very good results were encountered in $15(9.74 \%)$ of 154 legs treated with HS and good results were encountered in 83 (53.89\%) (Table II).

Comparing the good and very good results of LAS vs. HS, it was observed that for telangiectasias under $1 \mathrm{~mm}$ occurred in $95.05 \%$ of patients treated with LAS vs. $59.08 \%$ of patients treated with $\mathrm{HS}(\mathrm{RR}=9.72, \mathrm{P}<0.001)$. In the case of telangiectasias over $1 \mathrm{~mm}$ diameter, good and very good results occurred in $82.14 \%$ of patients treated with LAS vs. $67.03 \%$ of patients treated with $\mathrm{HS}(\mathrm{RR}=2.70 ; \mathrm{P}=0.003)$. The same comparison between POL vs. HS showed for telangiectasias under $1 \mathrm{~mm}$ diameter, $52.80 \%$ of legs treated with POL vs. $59.08 \%$ of legs treated with $\mathrm{HS}(\mathrm{RR}=1.65 ; \mathrm{P}=0.21)$. For telangiectasias over $1 \mathrm{~mm}$ diameter good and very good results occurred in $86.25 \%$ of legs treated with POL vs. $67.03 \%$ of legs treated with HS ( $\mathrm{RR}=1.44, \mathrm{P}=0.00756$ ) (Table II). At the first evaluation (at 60 days) results showed better results for POL vs. HS for telangiectasias over $1 \mathrm{~mm}$ comparing with LAS vs. HS ( $R R=3.57$, $\mathrm{P}<0.001$ comparing with $\mathrm{RR}=1.51, \mathrm{P}=0.066$ ) (Table I). The same evaluation for telangiectasias under $1 \mathrm{~mm}$ showed a 


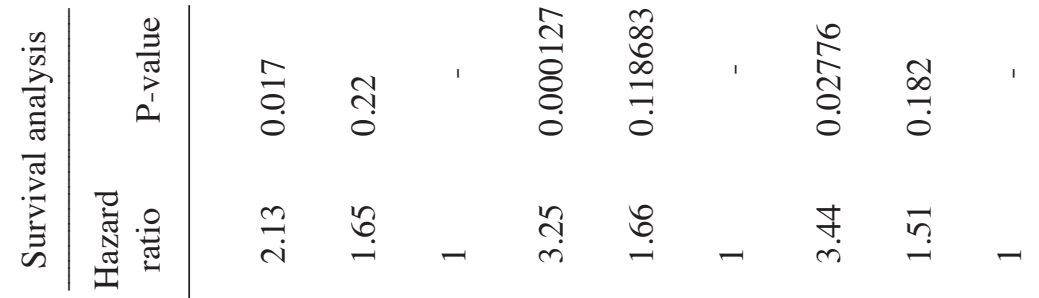

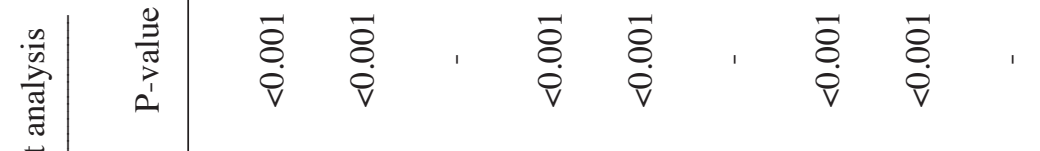

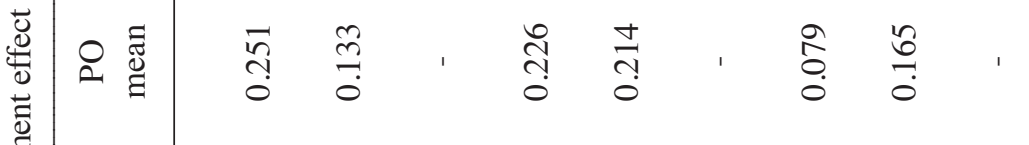

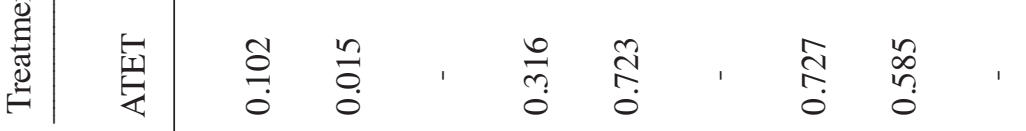

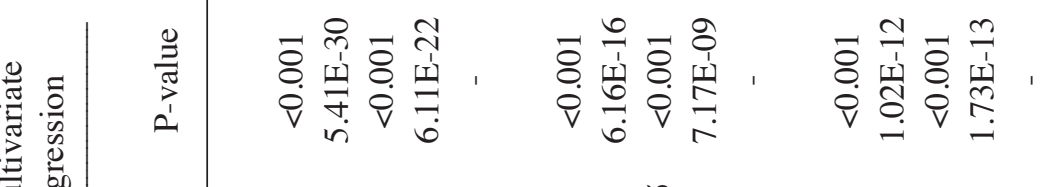

范莺

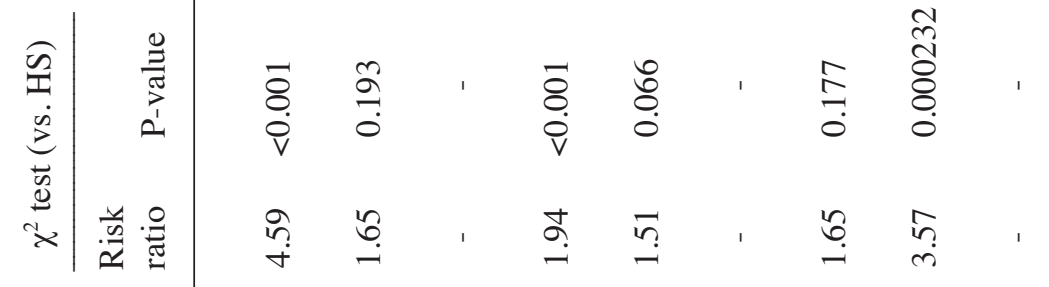

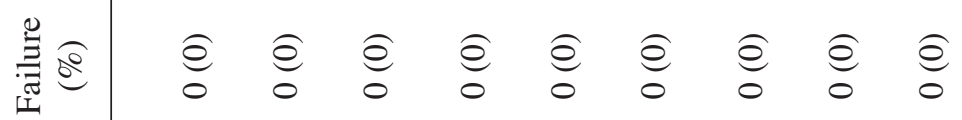

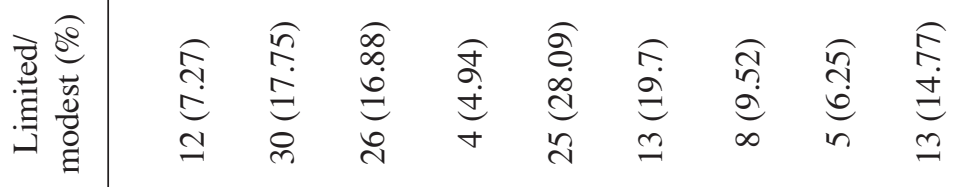

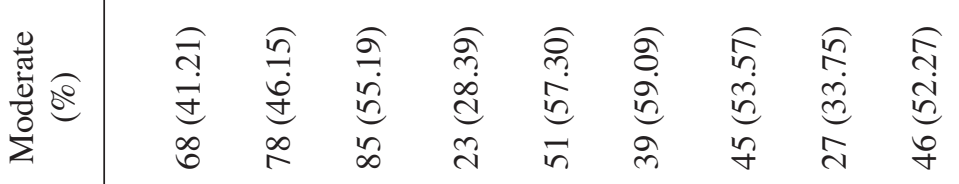

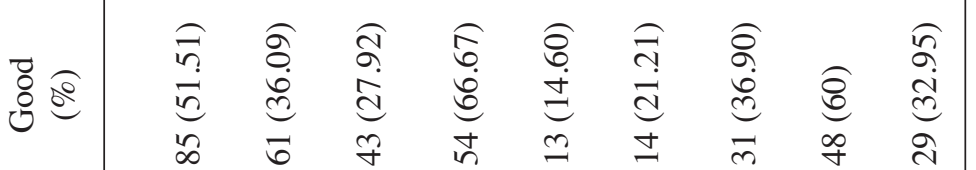

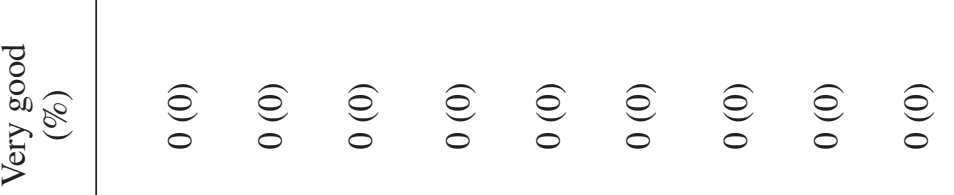




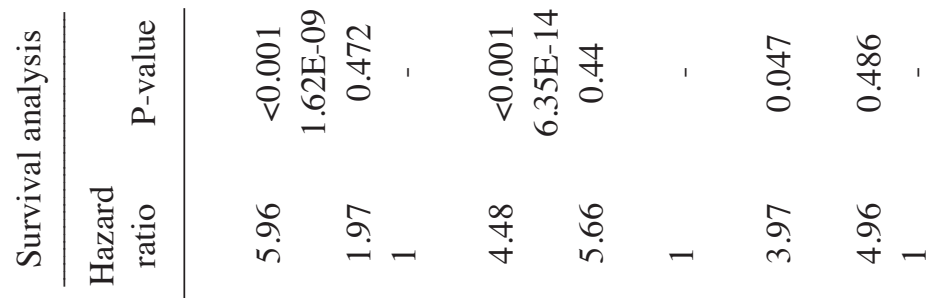

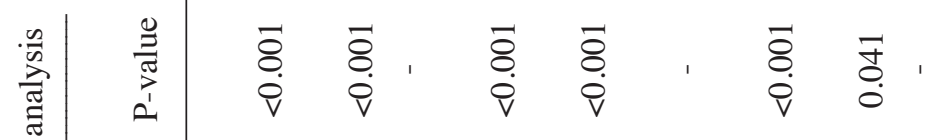

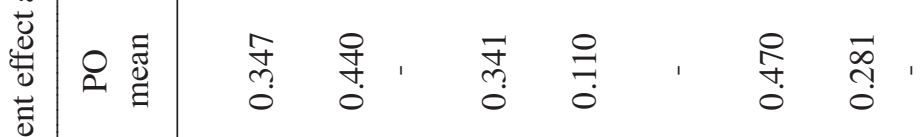

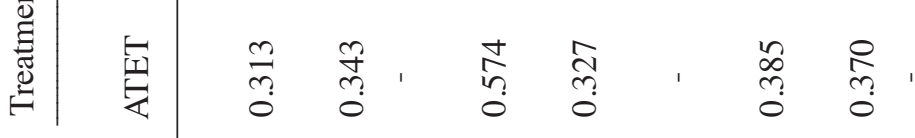

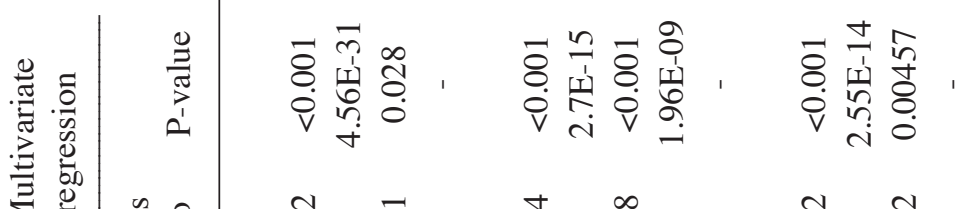

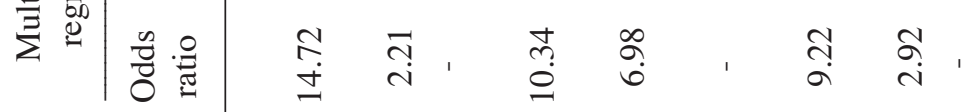

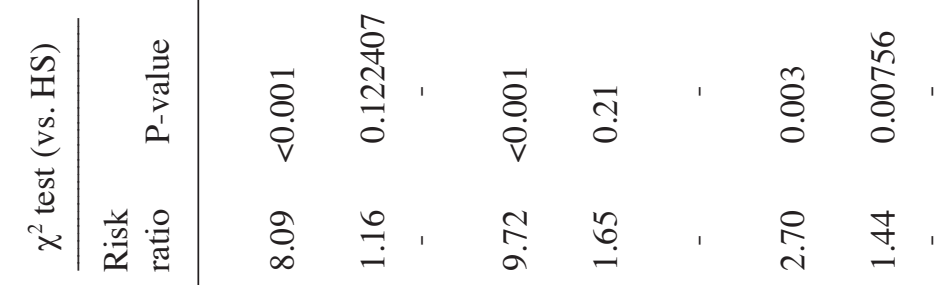

竞

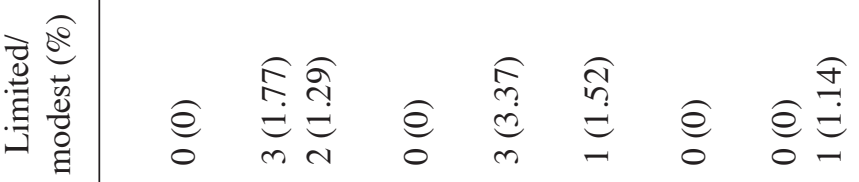

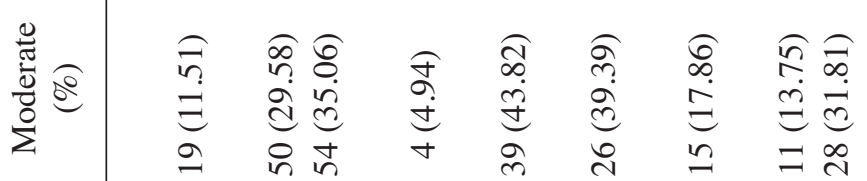

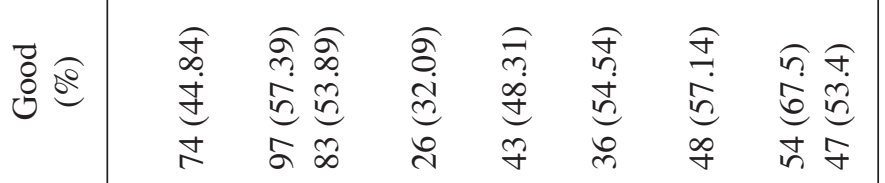

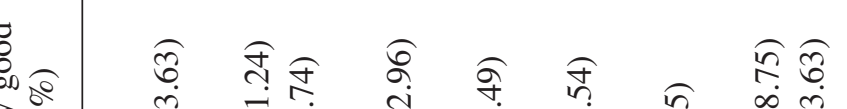

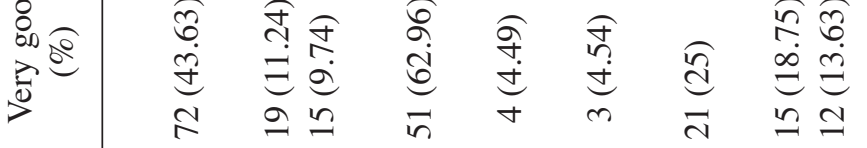

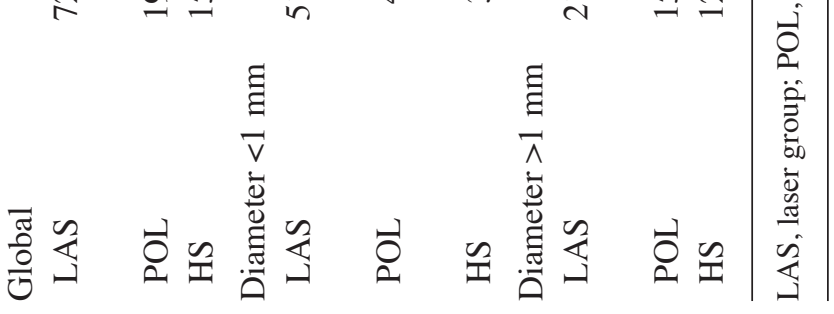


A

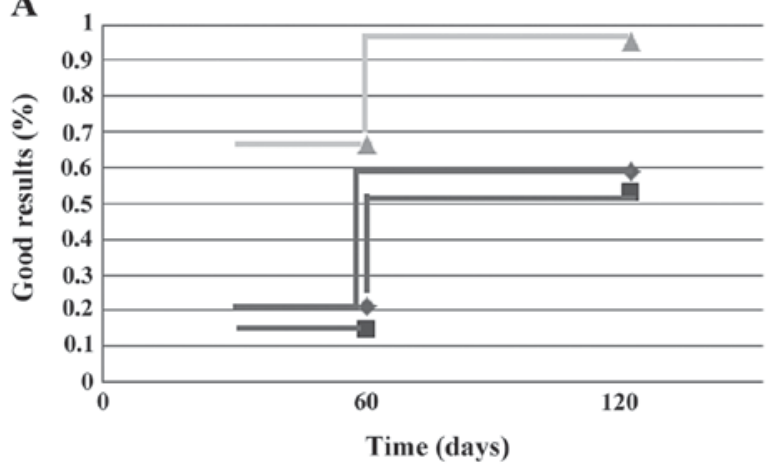

B

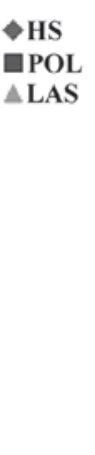

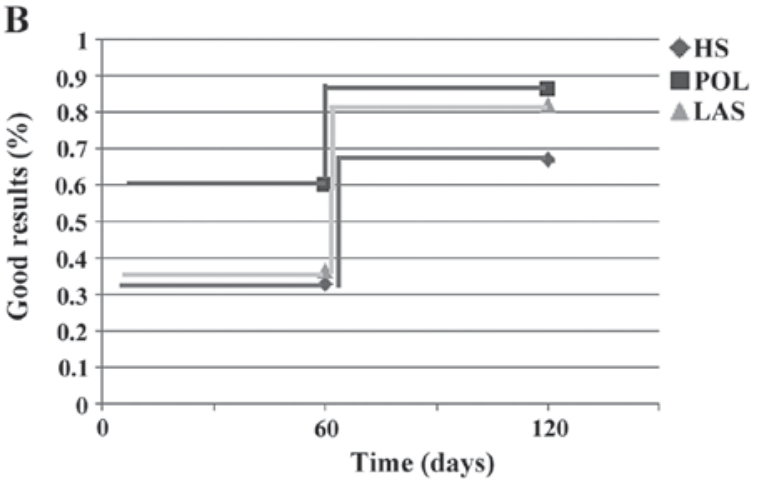

Figure 1. (A) The hazard function for the good effect of the 3 treatments in telangiectasias under 1 mm - Diam.1 (B) The hazard function for the good effect of the 3 treatments in telangiectasias over $1 \mathrm{~mm}$ - Diam.2 (LAS, laser group; POL, polidocanol group; HS, hypertonic saline group).

Table III. Longitudinal data analysis for good and very good results.

\begin{tabular}{lll}
\hline Treatment & 60 days $(\%)$ & 120 days $(\%)$ \\
\hline $\begin{array}{l}\text { Diameter }<1 \mathrm{~mm} \\
\text { LAS }\end{array}$ & $54(66.67)$ & $77(95.05)$ \\
POL & $13(14.60)$ & $47(52.80)$ \\
HS & $14(21.21)$ & $40(59.08)$ \\
Diameter $>1 \mathrm{~mm}$ & & \\
LAS & $31(36.90)$ & $69(82.14)$ \\
POL & $48(60.00)$ & $69(86.25)$ \\
HS & $29(32.95)$ & $59(67.03)$ \\
\hline
\end{tabular}

LAS, laser group; POL, polidocanol group; HS, hypertonic saline group.

better efficacy for LAS ( $\mathrm{RR}=1.94, \mathrm{P}<0.001$ comparing with $\mathrm{RR}=1.65, \mathrm{P}=0.177$ ) (Table I).

The results of the treatment effect analysis showed that in the treatment of telangiectasias under $1 \mathrm{~mm}$, LAS treatment had a higher potential outcome (PO) mean than POL treatment (0.341 vs. 0.110), whereas in telangiectasias over $1 \mathrm{~mm}$, LAS treatment had also a higher PO mean than the POL treatment (0.470 vs. 0.281$)$ (Table II).

Multivariate analysis compared the effect of applying the three types of treatments to the chance of obtaining a good result (separately for under and over $1 \mathrm{~mm}$ telangiectasias). For telangiectasias under $1 \mathrm{~mm}$ LAS treatment had an OR of 10.34 $(\mathrm{P}<0.001)$ and $\mathrm{POL}$ treatment of $6.98(\mathrm{P}<0.001)$ vs. HS treatment comparing with telangiectasias over $1 \mathrm{~mm}$ in which LAS had an OR of $9.22(\mathrm{P}<0.001)$ and the POL of $2.92(\mathrm{P}<0.00457)$ compared to HS treatment (Table II).

The longitudinal data analysis of the result showed that, for telangiectasias under $1 \mathrm{~mm}$, the good and very good results of LAS treatment occurred from the first treatment in 54 legs (66.67\%), and after the second in 77 legs $(95.05 \%)$, while for the POL treatment the results were $13(14.60 \%)$ and 47 legs $(52.80 \%)$. HS treatment achieved good results in 14 legs $(21.21 \%)$ in the first treatment and 40 legs after the second session (59.08\%) (Table III).
The hazard regression model showed a hazard ratio of 4.48 $(\mathrm{P}<0.001)$ for LAS and $5.66(\mathrm{P}=0.44)$ for POL. For telangiectasias under $1 \mathrm{~mm}$ LAS treatment is clearly superior to POL treatment, the latter having an insignificant coefficient. For telangiectasias over $1 \mathrm{~mm}$ the good and very good results of LAS treatment occurred after first session in 31 legs (36.90\%), and after the second in 69 legs $(82.14 \%$ ), while for the POL treatment, good and very good results occurred in 48 legs (60.00\%), respectively in 69 legs $(86.25 \%)$. HS treatment achieved good results in 29 legs (32.95\%), respectively in 59 legs (67.03\%) (Table III).

The hazard regression model showed a hazard ratio of 3.97 $(\mathrm{P}=0.047)$ for the LAS and $4.96(\mathrm{P}=0.486)$ for $\mathrm{POL}$ vs. HS treatment. We can conclude, for telangiectasias over $1 \mathrm{~mm}$ that a superiority of POL vs. LAS in terms of achieving good treatment results could not be demonstrated. Both types of treatments were well superior to HS treatment (Table II and Fig. 1).

In our study, for telangiectasias under $1 \mathrm{~mm}$, the LAS treatment determined a healing rate (telangiectasias disappearance) of 14.72 times higher than HS $(\mathrm{P}<0.001)$, while the POL treatment produced a healing rate of 11.32 times higher than HS $(\mathrm{P}<0.001)$.

\section{Discussion}

According to International Union of Phlebology, sclerotherapy represent an absolute indication in the treatment of telangiectasias and reticular veins $(5,9,10)$. If for larger blood vessel, foam sclerotherapy is more efficient, for telangiectasias liquid sclerotherapy is the best therapeutic choice $(5,10)$. In nonocclusive or premature recanalisation of the treated veins it may require several session of therapy (10). Several substances have been used for sclerotherapy. The main purpose being the destruction of the venous wall.

Hypertonic saline solution was the first option for this method, but nowadays it is used rarely due to discovery of more effective substances. The polidocanol (Lauromacrogol 400) is a non-ionic detergent but also with local anaesthetic action (11). This substance produces a chemical burn located at the injection site, in the endothelium of the vessel. The process is due to solubilisation of the lipoprotein compounds of the venous wall. The results are local inflammatory reaction followed by fibrosis, processes responsible for a complete closure of the injected vessel within 6-7 weeks. This way, the 
vessel is excluded from the blood circuit, bringing improvement of the symptoms caused by the varicose veins. Later on, the remodeling process will generate a good aesthetic outcome according to a minimal invasive treatment. The maximum accepted dosage is $2 \mathrm{mg} / \mathrm{kg} /$ day (5). Currently, there are available on the market polidocanol ampoules of $0.25,0,5,1,2$ and $3 \%$. The substance is administered intravenous, at the venous site, the concentration of it being chosen directly proportional with the vessel diameter $(10,11)$. Usually, the treatment of the telangiectasias and the reticular veins requires low concentrations of polidocanol, respectively $0.25 \%$, or $0.5 \%$, eventually even $1 \%$, but in some cases, higher concentrations can be used.

In our study, the group treated with saline solution was considered the reference group. We noted, similar results to polidocanol when treating telangiectasias smaller than $1 \mathrm{~mm}$ in diameter but an increased efficacy for polidocanol in case of larger vessels. The result can be explained by the fact that while for the very thin vessels, sclerotherapy is slightly inferior to laser treatment, the difference in efficacy between the 2 methods is extremely low so both are equivalent. For telangiectasias larger than $1 \mathrm{~mm}$ in diameter, where the best choice is sclerotherapy, the difference between polidocanol and saline solution is bigger as seen also in our study.

The current trend in modern medicine is to use when possible, minimal invasive treatment methods and with speedy recovery. While laser and intense pulse light became more popular in acne treatment or in many other skin diseases (12), these methods play the same role in treatment of telangiectasias of the lower limbs with certain criteria that limits the usage of sclerotherapy: telangiectasias on areas that had undergone surgery (telangiectatic matting, angiogenic flushing), vessel resistant to sclerotherapy, the impossibility of the catheterisation, needle-phobia and areas with increased risk of hyperpigmentation (13).

The minimal requirements of a laser used for treatment of telangiectasias are (13): i) a wavelength that is better absorbed by the haemoglobin in comparison with the surrounding chromophores; ii) the capacity for a deep penetration towards the vascular target; and iii) the capacity to transmit enough energy in order to be able to destroy the target, but without damaging the adjacent tissues. Different types of cooling devices have been developed for the skin surface that allow a higher transmission of the energy for a pan-endothelial destruction while reducing the negative effects of the skin. On the other hand, the cooling degree of the skin depends of the prototype, the lighter ones (Fitzpatrick I and II) needing more cooling time in comparison to darker skin (Fitzpatrick V and VI). Furthermore, the cooling systems decrease the pain, laser treatment being painful.

The $1064 \mathrm{~nm}$ wavelength of Nd:YAG laser is responsible for, on the one hand, an adequate absorption at the blood vessel levels (where haemoglobin is the main chromophore) and, on the other hand, a deeper penetration through the skin in comparison to shorter wavelengths and so being able to penetrate dermal and subdermal vessels. Moreover, it benefits from a low absorption of melanin and therefore it is suitable for treating a large variety of photo types (darker included) with decrease risk of depigmentation at the treated site. Due to all its features, Nd:YAG laser represents the best choice for treatment of the telangiectasias of the lower limbs (14).
We must differentiate the small red telangiectasias, that are superficial and contain a larger quantity of oxygenated haemoglobin and the blue-violaceous one, usually thicker, with lower amount of oxyhaemoglobin. If for the former we need high fluencies (350-600 J/ $\left.\mathrm{cm}^{2}\right)$, short pulse duration (15-30 $\mathrm{msec})$ and small spot size $(<2 \mathrm{~mm})$, for the latter larger spot size $(2-6 \mathrm{~mm})$ is recommended, lower fluencies (100$350 \mathrm{~J} / \mathrm{cm}^{2}$ ) and longer duration if the pulse is $30-50 \mathrm{msec}(15)$. We mentioned above the characteristics of the light spot we used in our study.

Sclerotherapy associated with laser may result in better outcome in selected cases. The literature shows numerous studies regarding the efficacy of different concentrations of polidocanol in treatment of varicose veins of the lower limbs (10). In our study we used hypertone saline solution in a number of cases considered as reference compared with other methods $(5,16,17)$.

An interesting study assessed Polidocanol 0.5\%, 1\%, sodium tetradecyl sulphate (STS) $1 \%$ and placebo in treatment of varicose veins $\mathrm{C} 1$ (18). The study permitted to repeat twice the injections at 3-week interval and also thrombectomy was accepted for a good aesthetic result. The efficacy of polidocanol was proven in comparison to placebo $(93.6 \%$ at $0.5 \%$ vs. $97.4 \%$ at $1 \%$ ) with a slight advantage to STS (96.3\%). In our single-blind study, laser was a variable. We chose not to perform thrombectomy, in order to maintain equal condition for both sclerotherapy and laser. Moreover, thrombectomy is rarely used for telangiectasias treatment.

There are plenty of studies that have assessed liquid sclerotherapy vs. foam $(10,19)$. The results are significantly better for foam in varicose veins $\left(\mathrm{C}_{2}\right)$, but in telangiectasias treatment the results are similar, statistically insignificant. In our study we used liquid form for both polidocanol and saline solution.

Complications are rare for laser and also for sclerotherapy. We refer to ulcerations that can occur after usage of both methods to treat telangiectasias. After sclerotherapy, ulcerations appear following perivascular injection (16). It is mandatory that the physician makes sure to inject intravascularly because perivascular penetration of the substance can lead to local necrosis or ulcerations, mainly in hypoderm reduced areas, near the bone structures. In most cases, perivascular injection determines local pain while the correct sclerotherapy, intravascularly, is painless. During laser treatment, ulcerations can develop due to the tendency of the physician to retreat the same areas either due to lack of immediate expected results, or to inappropriate adjustment of the fluency in the nearby bone areas (13). In our case, the rate of local complications was minimal and there was no need for complementary treatment, with spontaneous remission in all the patients. We must remember that sun protection is critical for a good aesthetic outcome.

After Nd:YAG laser, pain as short burn can develop immediately postoperative. Normally, analgesics are not needed. The immediate aesthetic results are impressive, small vessels (especially the violaceous ones) disappear completely, being visible also during the treatment session. Larger blue vessels can become darker in colour, postoperative but it will fade out in the following weeks. Sometimes, another laser session is needed on these vessels but not sooner than 2 months after the first treatment. Taking this into account, our study 
encompassed 2 visits, at 2-month interval, for both laser and sclerotherapy.

After laser treatment, the edema is usually minimal and lasts a few days. Also, erythema is present for 2-3 weeks depending on the fluency and the sensitivity of the area of the lower limbs. While compression stocking role after sclerotherapy is certain, after Nd:YAG laser this is, most of the times, not recommended. Usually it is advised to apply hydrating creams and cold compresses during the first days after the treatment. We did not use compression post sclerotherapy to maintain a balance between the two methods and due to lack of recommendations for compression after sclerotherapy of the small vessels (such as telangiectasias) (10).

Hyperpigmentation after Nd:YAG laser is rare. Theoretically, hypopigmentation can occur because of the light absorption by the melanin, but normally the phenomenon is reduced so the depigmentation risk is also low.

In conclusion, telangiectasias and reticular veins of the lower extremities can be successfully treated with Nd:YAG laser or sclerotherapy with polidocanol. Nd:YAG laser is recommended for treatment of small telangiectasias, less than $1 \mathrm{~mm}$ in diameter, while sclerotherapy with polidocanol is more efficient as the dimensions of the vessels grow.

\section{Acknowledgements}

Not applicable.

\section{Funding}

No funding was received.

\section{Availability of data and materials}

The datasets used and/or analyzed during the current study are available from the corresponding author on reasonable request.

\section{Authors' contributions}

GI, SI, MXCP and DN contributed to the conception and design of the study, acquisition, analysis and interpretation of the data. CT and DC were responsible for the design, analysis of the data and critical revision of the study for important intellectual content. All authors read and approved the final version of the manuscript.

\section{Ethics approval and consent to participate}

The study was conducted in accordance with the World Medical Association Declaration of Helsinki and approved by the Institutional Ethics Committee of the Medical Center Dr. Ianosi (no. ETIC 6/2016; Craiova, Romania), and informed written consent was obtained from each patient.

\section{Patient consent for publication}

Not applicable.

\section{Competing interests}

The authors declare that they have no competing interests.

\section{References}

1. Van der Velden SK, Shadid NH, Nelemans PJ and Sommer A: How specific are venous symptoms for diagnosis of chronic venous disease? Phlebology 29: 580-586, 2014.

2. Tudoraşcu I, Sfredel V, Riza AL, Dănciulescu Miulescu R, Ianoşi SL and Dănoiu S: Motor unit changes in normal aging: A brief review. Rom J Morphol Embryol 55: 1295-1301, 2014.

3. Breu FX and Wollmann JC: Clinical and technical follow-up after sclerotherapy. Dermatol Surg 36 (Suppl 2): 1004-1009, 2010.

4. Heck M, Faulhaber J, Breu FX and Schneider SW: Foam sclerotherapy. Uses and indications in dermatology and phlebology. Hautarzt 63: 493-505, 2012 (In German).

5. Perrin M, Eklof B, VAN Rij A, Labropoulos N, Vasquez M, Nicolaides A, Blattler W, Bouhassira D, Bouskela E, Carpentier P, et al: Venous symptoms: The SYM Vein Consensus statement developed under the auspices of the European Venous Forum. Int Angiol 35: 374-398, 2016

6. Hamel-Desnos C, Ouvry P, Benigni JP, Boitelle G, Schadeck M, Desnos P and Allaert FA: Comparison of $1 \%$ and $3 \%$ polidocanol foam in ultrasound guided sclerotherapy of the great saphenous vein: A randomised, double-blind trial with 2 year follow-up. 'The 3/1 Study'. Eur J Vasc Endovasc Surg 34: 723-730, 2007.

7. Chen $\mathrm{CH}$, Chiu $\mathrm{CS}$ and Yang $\mathrm{CH}$ : Ultrasound-guided foam sclerotherapy for treating incompetent great saphenous veins - results of 5 years of analysis and morphologic evolvement study. Dermatol Surg 38: 851-857, 2012.

8. Prieto V, Zhang P and Sadick NS: Comparison of a combination diode laser and radiofrequency device (Polaris) and a long-pulsed 1064-nm Nd:YAG laser (Lyra) on leg telangiectases. Histologic and immunohistochemical analysis. J Cosmet Laser Ther 8: 191-195, 2006

9. Caruntu C, Negrei C, Boda D, Constantin C, Caruntu A and Neagu M: Biotechnological advances for diagnosis of peripheral diabetic neuropathy. Rom Biotech Lett 19: 9846-9858, 2014.

10. Breu FX, Guggenbichler S and Wollmann JC: 2nd European Consensus Meeting on foam sclerotherapy 2006, Tegernsee, Germany. Vasa 37 (Suppl 71): 1-29, 2008.

11. Goldman MP, Guex JJ and Weiss RA (eds): Sclerotherapy: Treatment of Varicose and Telangiectatic Leg Veins. 5th edition. Saunders, Philadelphia, pp1-416, 2011.

12. Ianosi S, Neagoe D, Calbureanu M and Ianosi G: Investigator-blind, placebo-controlled, randomized comparative study on combined vacuum and intense pulsed light versus intense pulsed light devices in both comedonal and papulopustular acne. J Cosmet Laser Ther 15: 248-254, 2013.

13. Nijsten T, van den Bos RR, Goldman MP, Kockaert MA, Proebstle TM, Rabe E, Sadick NS, Weiss RA and Neumann MH: Minimally invasive techniques in the treatment of saphenous varicose veins. J Am Acad Dermatol 60: 110-119, 2009.

14. Guex JJ, Schliephake DE, Otto J, Mako S and Allaert FA: The French polidocanol study on long-term side effects: A survey covering 3,357 patient years. Dermatol Surg 36 (Suppl 2): 993-1003, 2010.

15. Sadick NS: Laser treatment of leg veins. Skin Therapy Lett 9: 6-9, 2004.

16. Rabe E, Breu FX, Cavezzi A, Coleridge Smith P, Frullini A, Gillet JL, Guex JJ, Hamel-Desnos C, Kern P, Partsch B, et al; Guideline Group: European guidelines for sclerotherapy in chronic venous disorders. Phlebology 29: 338-354, 2014.

17. Branisteanu DE, Nichifor M, Dorobat CM, Branisteanu DC, Petrariu FD, Molodoi AD, Radu DC and Boda D: Use of textile biomaterials for the topic treatment of chronic venous disease. Rom Biotechnol Lett 20: 10618-10625, 2015.

18. Rabe E, Schliephake D, Otto J, Breu FX and Pannier F: Sclerotherapy of telangiectases and reticular veins: A doubleblind, randomized, comparative clinical trial of polidocanol, sodium tetradecyl sulphate and isotonic saline (EASI study). Phlebology 25: 124-131, 2010.

19. Uncu H: Sclerotherapy: A study comparing polidocanol in foam and liquid form. Phlebology 25: 44-49, 2010. 